PRONUNCIAMENTO

\title{
ABERTURA DO 12 CONGRESSO BRASILEIRO DE DESIGN 2016
}

Dijon De Moraes

Reitor da Universidade do estado de Minas Gerais - UEMG

dijon.moraes@uemg.br

Bom dia a todos os presentes

Prezada Profa. Carolina Marra Simões Coelho, Vice-reitora do Centro Universitário UNA, parceira da UEMG na realização deste 12 ․ Congresso Brasileiro de Pesquisa e Desenvolvimento em Design - P\&D 2016. Agradecemos a parceria da UNA e a disponibilidade de suas dependências.

Prezado Prof. Ricardo Triska, Coordenador da área de arquitetura e urbanismo e design junto à CAPES.

Prezado Prof. Evaldo Ferreira Vilela, Presidente da Fundação de Amparo à Pesquisa do Estado de Minas Gerais - FAPEMIG;

Prezado Prof. Márcio Portes, Subsecretário de Ensino Superior da Secretaria de Estado de Desenvolvimento Econômico, Ciência, Tecnologia e Ensino Superior - SEDECTES;

Prezado Prof. José Eustáquio de Brito, Vice-reitor da Universidade do Estado de Minas Gerais - UEMG;

Prezada Profa. Giselle Safar, Pró-reitora de Extensão da UEMG;

Prezado Prof. José Arnaldo da Mata Machado, Diretor da Escola de Design da UEMG;

Prezada Profa. Rita Engler, Coordenadora do Programa de Pós-Graduação em Design da UEMG e Coordenadora do 12 ㅇ Congresso Nacional de Pesquisa e Desenvolvimento em Design, o P\&D 2016.

Em nome de quem cumprimento também todo o Comitê Cientifico, o Comitê Avaliador e todos os membros da Comissão Local Organizadora deste importante evento.

Meus cumprimentos também aos palestrantes Profa. Paola Bertola (Politécnico di Milano); Federico Hess (Tecnológico de Monterrey - Cidade do México); Maria Cecilia Loschiavo Santos (USP) e Maria Veronica Barzola (Universidade de Palermo, Argentina). 


\section{Senhoras e Senhores,}

É com grande satisfação que hoje faço a abertura oficial do 12 Congresso Brasileiro de Pesquisa e Desenvolvimento em Design - P\&D 2016.

Este evento de caráter acadêmico-cientifico em nível da Pós-graduação no Brasil, teve seu início no ano de 1994, sendo a sua primeira edição realizada na cidade de São Paulo. Uma iniciativa da Associação de Ensino em Design do Brasil - Aend-BR e, da Revista Cientifica Estudos em Design sediada na PUC-Rio. Vale, oportunamente, recordar, que o primeiro P\&D ocorreu simultaneamente ao 10 Congresso Brasileiro de Design, promovido pela Associação Nacional de Designers - AND e pela própria AEnd.

Tenho a honra em dizer que estava presente nestes dois pioneiros eventos ocorridos em São Paulo em 1994 e, gostaria de registrar o meu reconhecimento aos profissionais e pesquisadores em design ali presentes, mesmo correndo o risco de omitir alguns dos colegas que lançaram a semente destes primeiros congressos em Design no Brasil e que ali se encontravam fazendo história, dentre eles: Ana Maria de Moraes, Gustavo Amarante Bonfim, Rita Couto, Álvaro Guilhermo, Itiro lida, Ivens Fontoura, Maria Cecília Loschiavo, Lucy Niemeyer, Auresnedes Pires Stefhan, João Roberto Peixe, Fred Van Camp, Joaquim Redig, Virginia Kistmann, Eduardo Barroso, Marcelo Resende, Bernadete Teixeira, Ari Rocha, João Bezerra de Menezes, Alfredo Jefferson, Vera Damazio, Cristine Nogueira, Guilherme Cunha Lima e sua companheira de vida e de sonhos Edna Cunha Lima. O Guilherme, hoje aqui merecidamente homenageado, foi do "Gráfico Amador" à sistematização do design como atividade profissional no Brasil. Meus parabéns Guilherme.

Na sequência do evento em São Paulo, o P\&D foi realizado em 1996 aqui em Belo Horizonte, nas dependências da nossa emblemática Escola de Design já como UEMG mas, ainda no mesmo local onde funcionava a Fundação Universidade Mineira de Arte, a pioneira FUMA, instituição formadora de tantos talentos e de protagonistas de expressão nacional no âmbito do design brasileiro. De periodicidade bienal, o P\&D percorreu este vasto país, levando o seu húmus rico e fértil para semear a pesquisa em design em diferentes regiões e Universidades por todo o Brasil.

Esse grande congresso representa a festa maior do conhecimento, estudo e pesquisa em design em território nacional e, a Revista Estudos em Design que registrou seus primeiros Anais, hoje é a nossa publicação mais bem avaliada junto à CAPES, contemplada com o Qualis A2.

No ano 2014, após já contabilizarmos vinte anos de Congresso P\&D e vinte e um anos do Periódico Estudos em Design, foi promovida a publicação de uma Edição Especial Comemorativa com o sugestivo tema: "20 Anos do Programa de Pós-Graduação em Design no Brasil". 
Tive a honra de estar entre os articulistas convidados para escrever nesta histórica edição, como um dos representantes da região Sudeste do Brasil. Nesta oportunidade abordei o tema: "Pós-Graduação em Design no Brasil - Cenários e Perspectivas". Texto onde busquei manter o espírito maior da pós-graduação stricto sensu, que é o da investigação em design em nível avançado, mas que também nos permite uma postura reflexiva, analítica e crítica sobre a cultura produtiva e tecnológica e seus efeitos para a nossa sociedade.

Nesta oportunidade trouxe à luz os novos desafios para produtores e designers, da atualidade, ao atuarem em cenários mutantes e complexos, onde o design deixa o âmbito tecnicista e linear, passando à arena pouco conhecida e ainda codificada dos atributos intangíveis dos bens e artefatos de produção industrial.

Isto faz com que o design interaja, de forma transversal, com disciplinas cada vez menos objetivas e exatas, passando a confluir com outras que compõem o ambíguo e complexo terreno do comportamento humano. A complexidade no design também se caracteriza pela inter-relação recorrente entre a abundância das informações hoje facilmente disponíveis e desconectadas que, através de bruscas transformações, impõe contínuas adaptações e pede uma reorganização do sistema em nível de produção e consumo.

Acreditamos que um novo modelo propedêutico para as escolas de design tende a ser múltiplo, deve ser transversal e atravessável, deve fornecer conteúdos culturais, históricos, críticos e reflexivos em maior escala de formação. Uma escola com valores mais humanistas que tecnicistas e, com mais conteúdos experimentais e inovadores que lineares e previsíveis.

Considerando que os primeiros programas em nível stricto sensu em design no Brasil, surgiram a partir dos anos noventa com forte ênfase em um cenário ainda estático do passado, colocamos para reflexão, também nesta oportunidade, a existência de sintonia entre os cursos de pós-graduação stricto sensu existentes no Brasil com a realidade social, mercadológica e produtiva da atualidade, onde prevalece um cenário fluido e dinâmico muitas vezes ainda incompreensível e desconexo.

Por isso hoje, gostaria de colocar três questões para nossa reflexão na complexa e fuzzi realidade do design contemporâneo ora estabelecida:

A primeira questão trata-se da atual dificuldade de definição do termo design. Definição essa que seja coesa, abrangente e facilmente compreensível para o seu próprio entendimento como atividade projetual dentro da área de conhecimento das Ciências Sociais Aplicadas. É interessante notar que ironicamente o antigo mote: "defina primeiro o problema", deu lugar ao "defina primeiro o design" pois, de qual design hoje falamos? 
A segunda diz respeito ao controle ou pelo menos a organização dos próprios contornos do design, que thes assegure um fácil reconhecimento como área de conhecimento próprio, apesar da sua natural condição de atividade múlti e interdisciplinar.

A terceira questão trata-se da sua transversalidade que lhes possibilita receber contribuições de diferentes âmbitos profissionais e de distintas áreas do conhecimento, oriundas de diversas atividades que além, obviamente, de contribuir para seu crescimento e amplitude, culmina, por outro lado, por the conferir sempre novas fronteiras e novos campos de ação, promovendo, por fim, constantes questões abertas que nunca se fecham.

Essas três reflexões, aqui apresentadas, vão ao encontro da realidade atual do "design" que, coerentemente com a era do conhecimento, se desvinculou do termo "industrial". Abrindo assim, suas fronteiras, para novas possibilidades e aproximações nem sempre compreensíveis e sedimentadas, fazendo do design uma atividade cada vez mais ampla, abrangente e complexa.

Confesso não haver respostas precisas para as questões mas, coloco as perguntas na tentativa de pelo menos organizar as indagações.

Gostaria, nesta oportunidade, deixar estas demandas como uma reflexão a tantos pesquisadores e estudantes aqui presentes (que superaram o número de mil e trezentos inscritos), convocando todos para refletir e debater sobre as interrogações presentes nessa fascinante atividade durante os quatro dias de Congresso que ora se inicia.

Tive a grata satisfação de participar de quase todos os Congressos Brasileiro de Pesquisa em Design e, que foram realizados em diferentes regiões e Universidades do Brasil. Oportunidade esta em que apresentei trabalhos, realizei palestras, minicursos e workshops, fui membro de Comissões Cientificas e de Comissões Avaliadoras mas, nunca imaginei, nem nas mais íntima prospecção pessoal, que um dia estaria realizando a open lecture de um Congresso Brasileiro de Design na condição de reitor/designer ou de designer/reitor de uma Universidade anfitriã.

Mas, dentro do seu intelecto ativo e fascinante conteúdo o design também promove essas surpresas,

Muito obrigado.

\section{DIJON DE MORAES}

